\title{
Improving biomecanics in removable partial dentures with implants Clinical report -8 years follow-up
}

Nuno Sampaio, Filipe Moreira, Luis Alves, Fernando Guerra, Pedro Nicolau,

Faculty of Medicine, University of Coimbra, Portugal

Oral rehabilitation of edentulous distal areas with removable partial dentures (RPD) is a demanding clinical challenge. These oral rehabilitations have sometimes muco-dental support due to the absence of teeth in the posterior areas (Kennedy class I - bilateral free end and Kennedy class II -unilateral free end). Oral rehabilitation of such cases (Kennedy classes I and II) with RPD is generally associated with some problems, such as: lack of stability, minimal retention, discomfort when loading, pain on abutment teeth and frequent need of relining. There are several articles supporting that implants in such edentulous spaces are viable and should be an option under certain conditions

\section{CLINICAL REPORT AND CONSIDERATIONS}

A 36 year old female patient, with a partially edentulous atrophic maxilla was submitted to maxillofacial surgery to correct a skeletal class III malocclusion in June 2008 and 1 year after rehabilitated with implants and a RPD at the Faculty of Medicine, University of Coimbra, Portugal. In order to proceed with the treatment, the patient imposed some conditions: no bone grafting, sinus floor elevation or any kind of tissue graft. She also asked for a fixed rehabilitation at least in the aesthetic zone. Therefore a fixed anterior bridge on implant positions 12-22(FDI) and RPD supported by teeth 13, 23(FDI) and implants in positions 18 and 28 (FDI)

INITIAL CASE
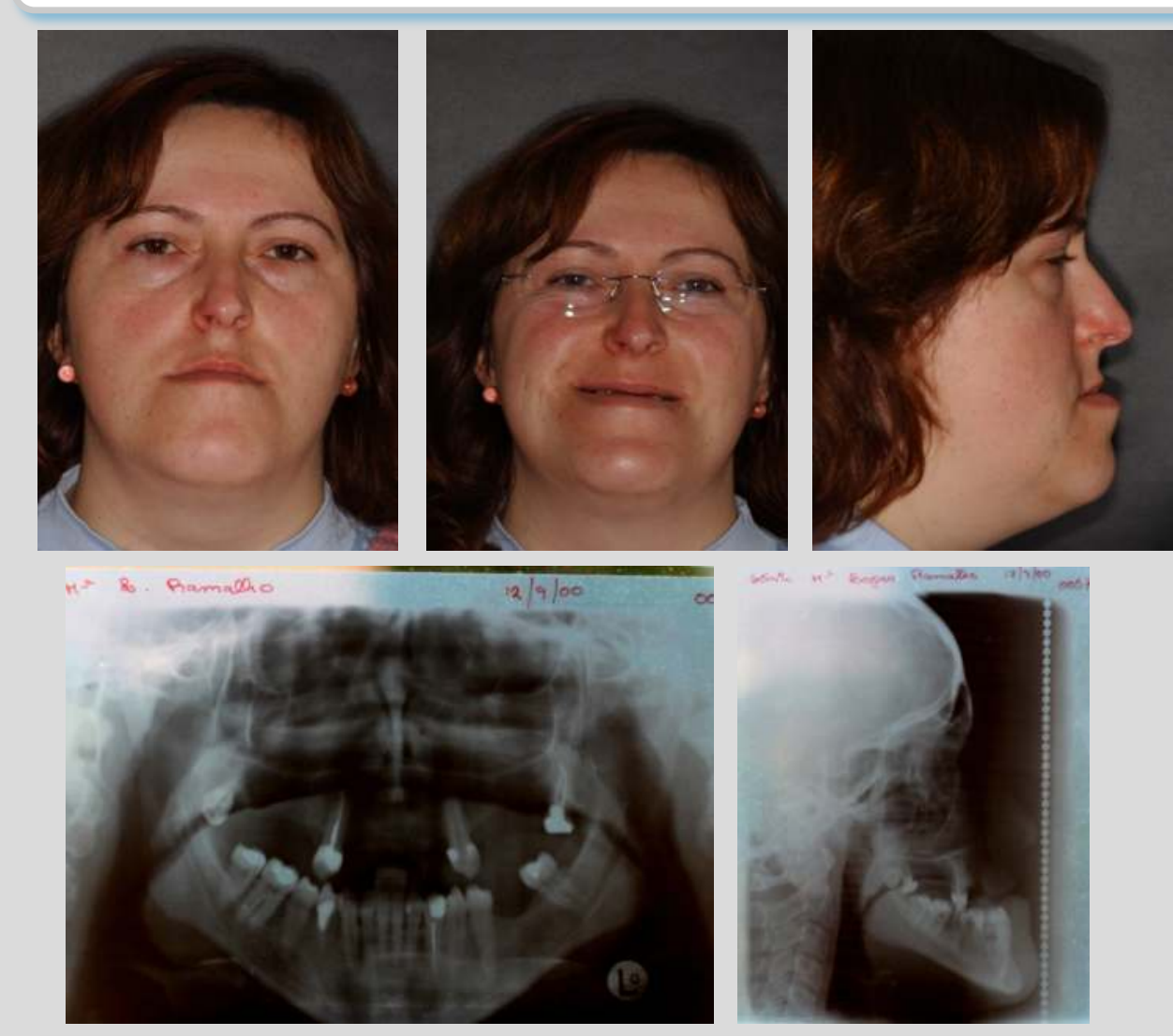

.
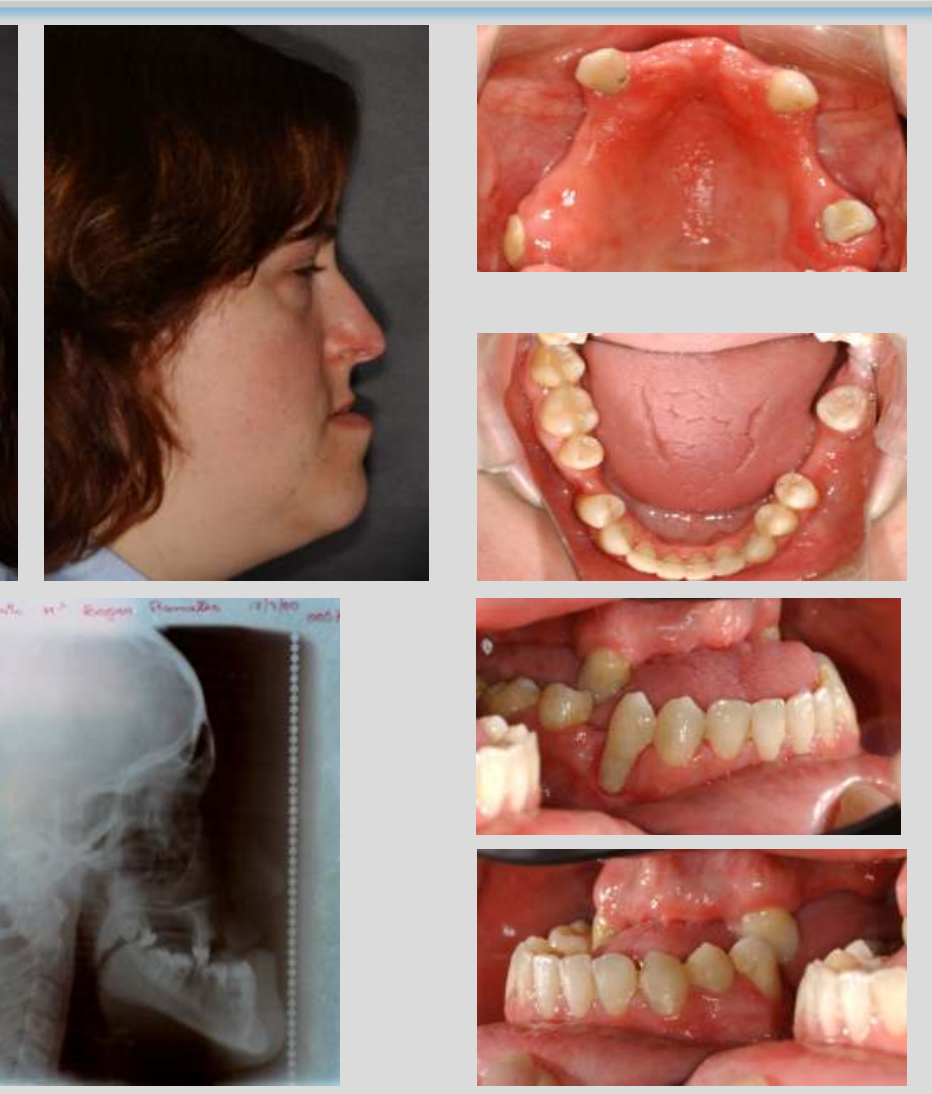

POST OP CONTROL, INITIAL AND DELAYED PROVISIONAL
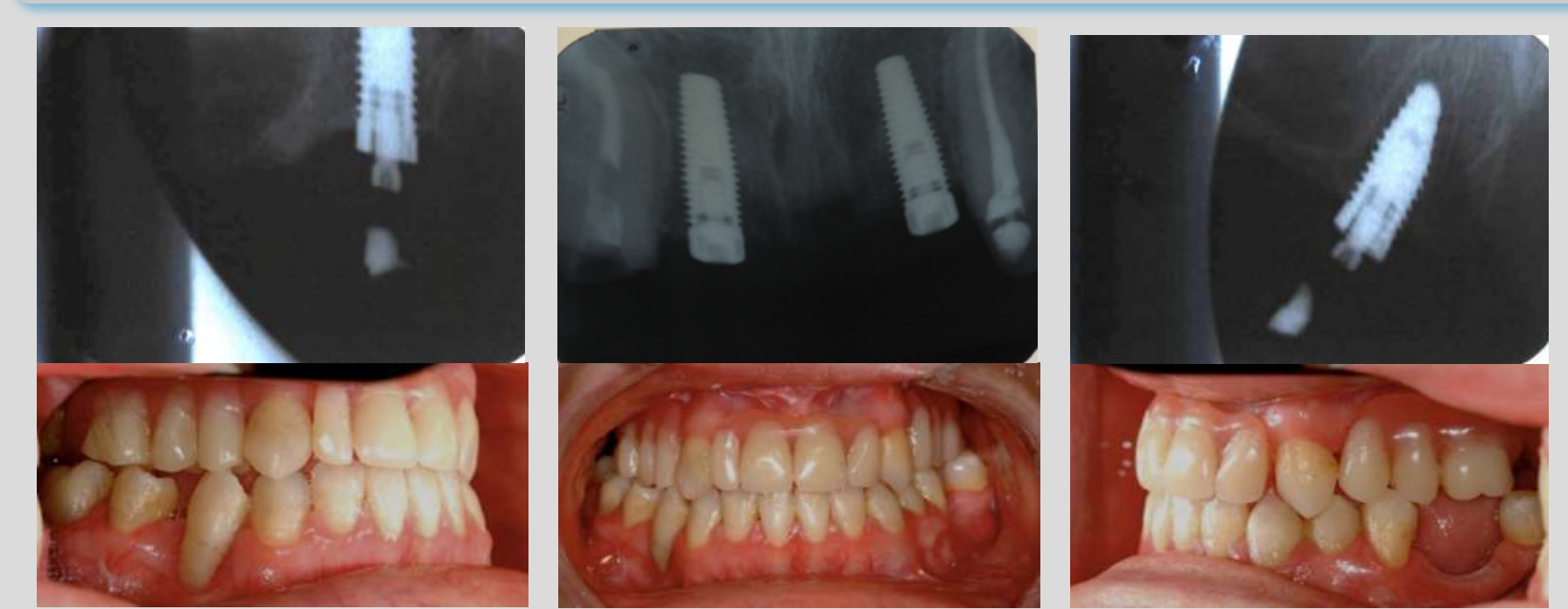

ESTHETIC AND FUNCTIONAL TRY IN
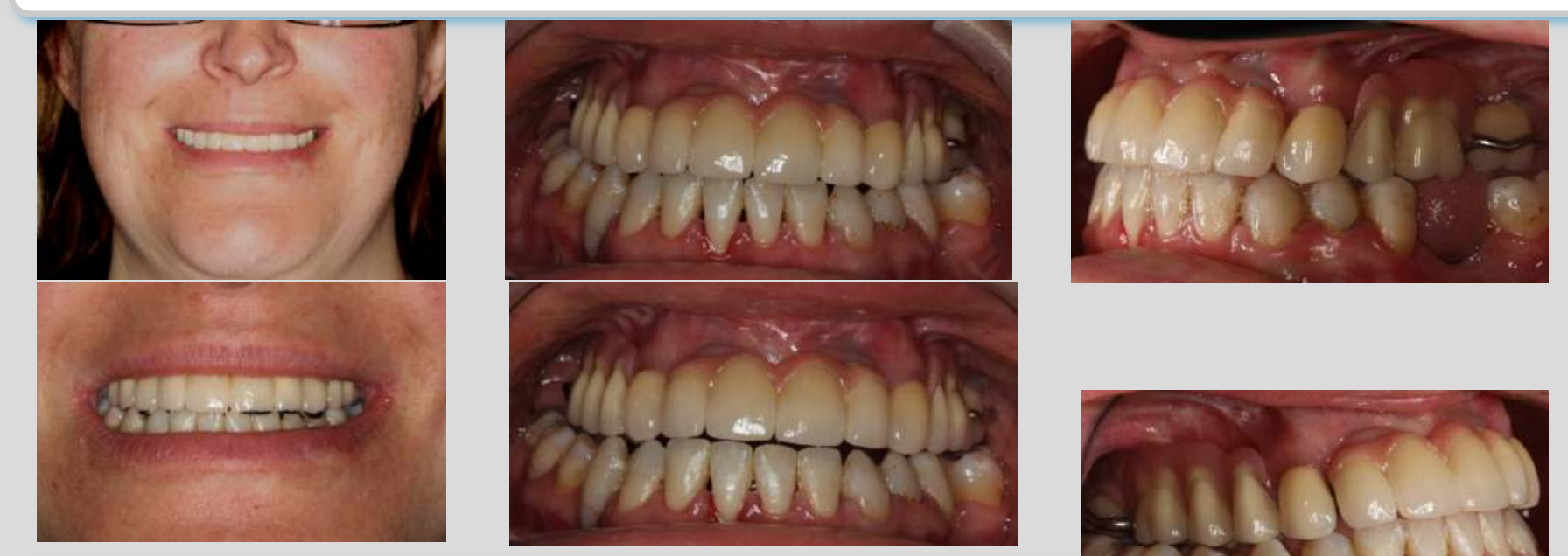

8 YEAR FOLLOW UP
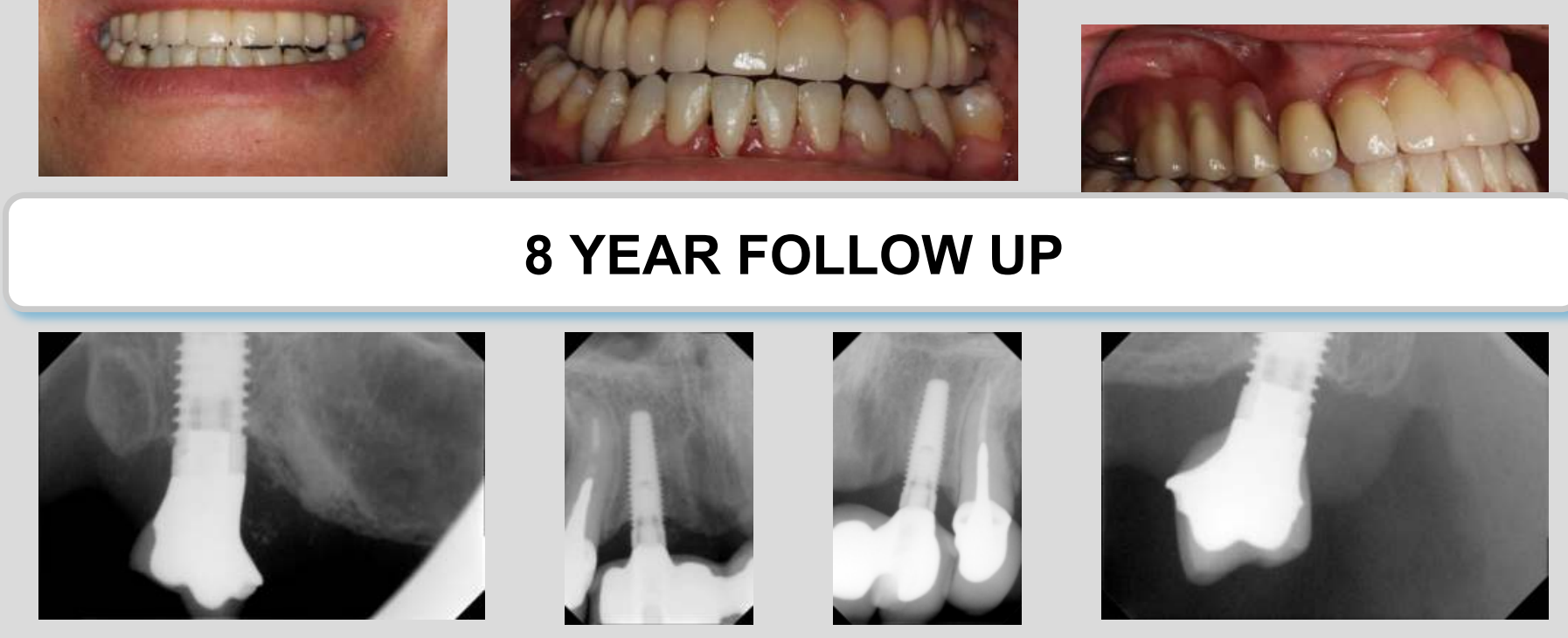

\section{REFERENCES}

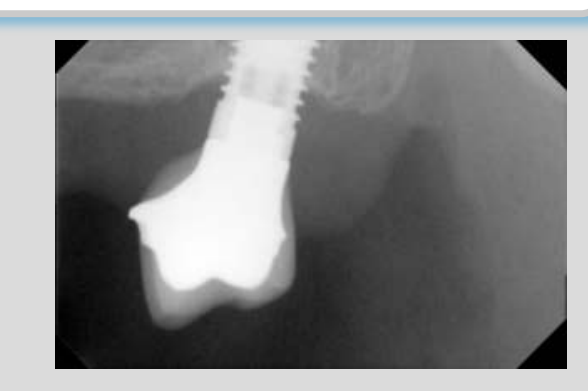

A systematic review of the survival and complication rates of fixed partial dentures (FPDs) after an observation period of at
least 5 years. II. Combined tooth-implant-supported FPDs. Lang NP, Pjetursson BE, Tan K, Brägger U, Egger $\mathrm{M}$, Zwahlen M. Clin Oral Implants Res. 2004 Dec; $15(6): 643-53$.
Implant-retained removable partial dentures: an 8-year retrospective study. Bortolini S, Natali A, Franchi M, Coggiola A, Consolo
1Y After MAXILLOFACIAL SURGERY ( Skeletal Class III)
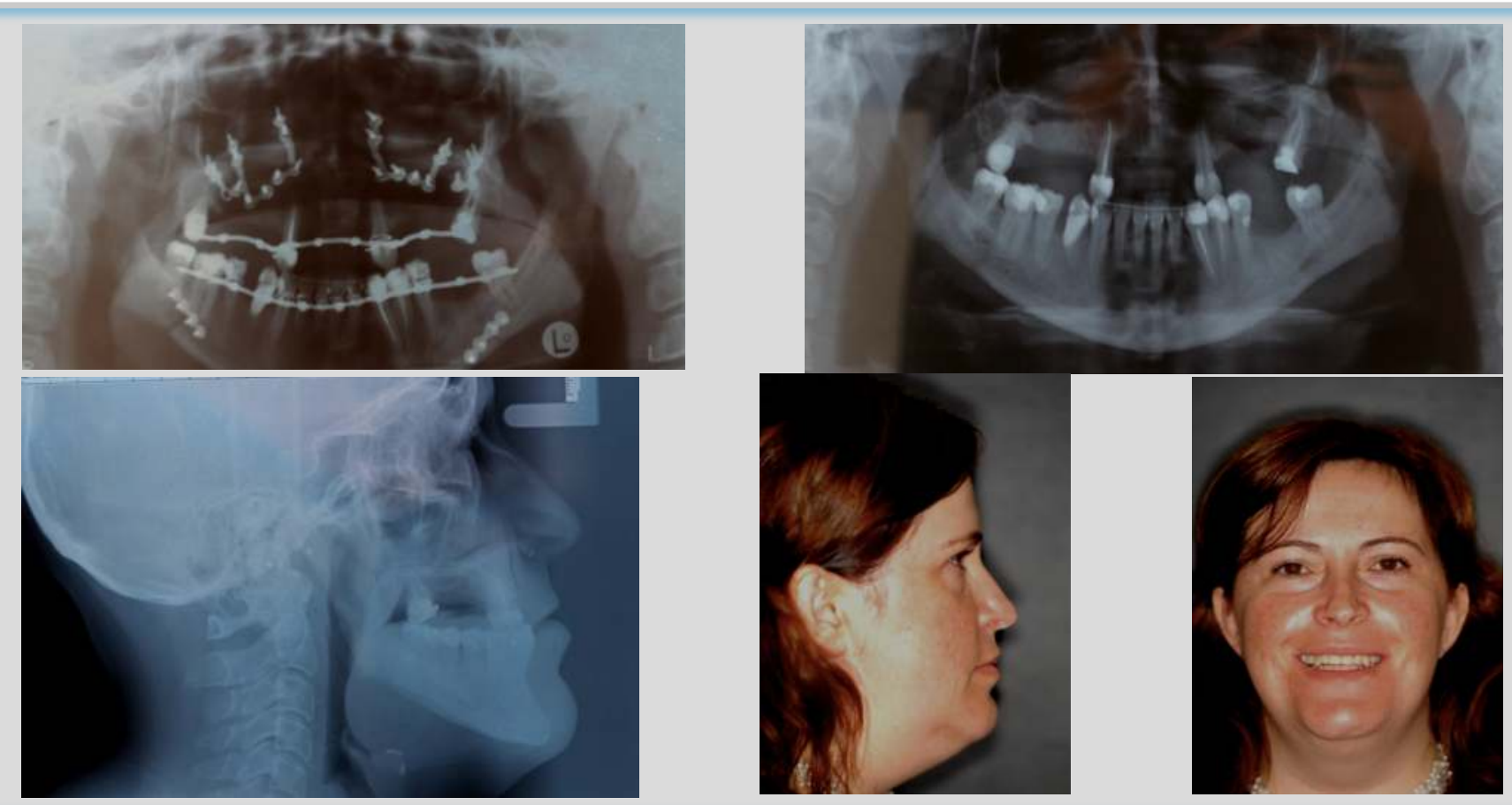

DEFINITIVE IMPRESSION AND TRY IN

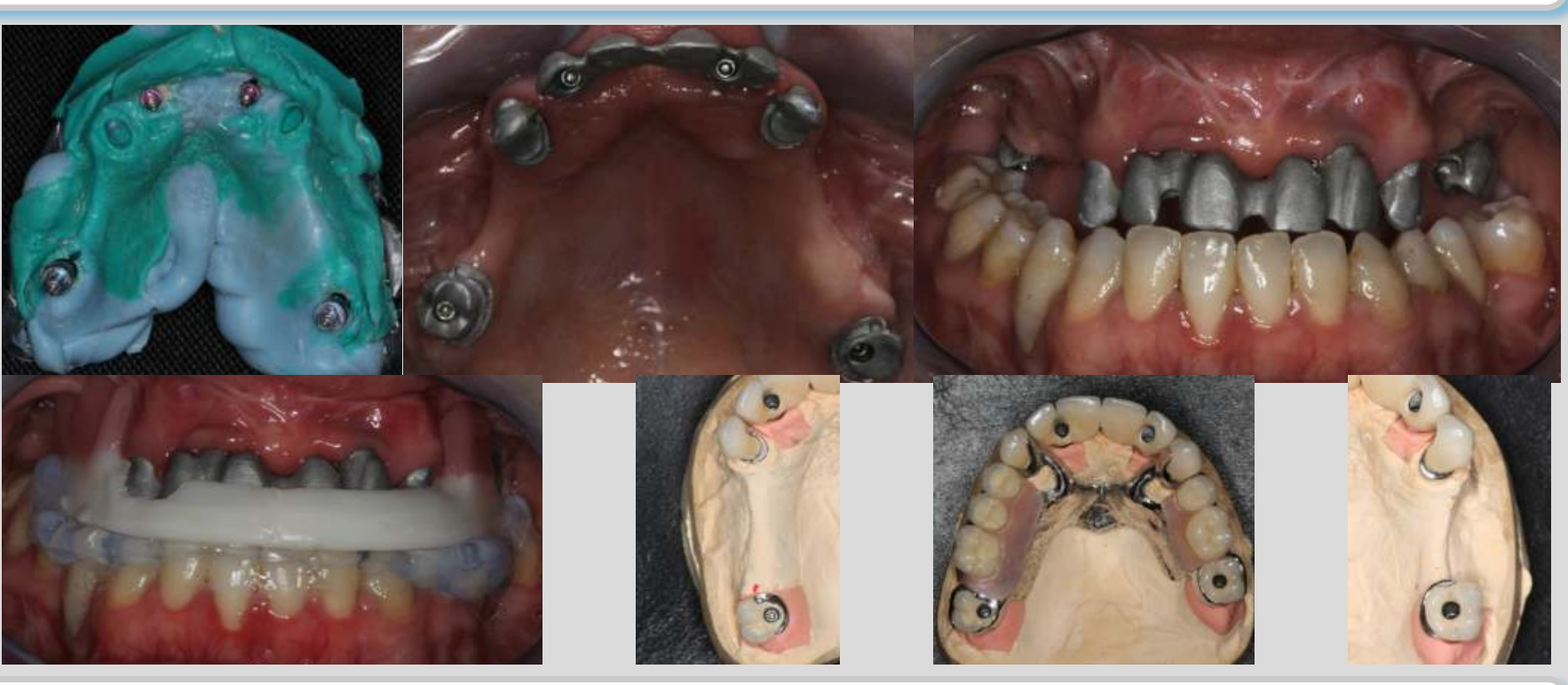

INSERTION AND X RAY

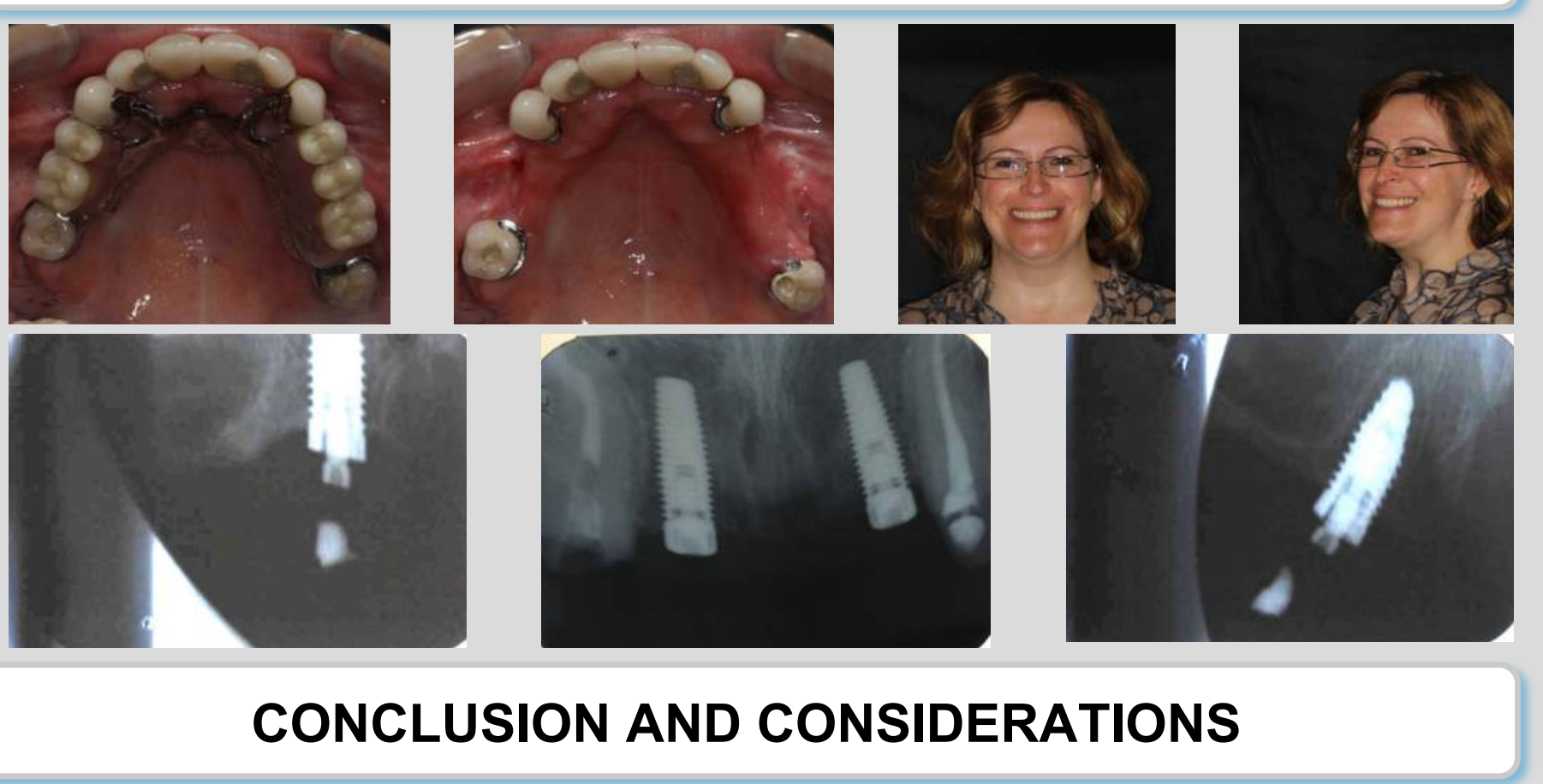

After reviewing the literature, a RPD supported by implants was the best treatment, regarding all limits imposed by the patient

After 8 years we still have a stable condition (biologic and mechanical) Rehabilitation of edentulous distal extension edentulous area with RPD is a challenge, but the prognosis can be highly improved with implants in posterior regions ( whether providing support or/and retention)

There are few articles in literature supporting that connecting implants and teeth is viable but there is a lack of evidence on the best approach in the nature of the connection

There are also some articles supporting the placement of dental implants to improve support in distal edentulous area, but still evidence is missing We believe that this modification of the oral condition improves highly patient satisfaction and prevent the need of constant relining, maintaining bone level more stable.

This kind of treatment should be used in oral rehabilitation of Kennedy classes I and II in order to avoid some problems and discomfort during function. 